\title{
Recomendaciones para la realización, presentación, edición y publicación de trabajos académicos en revistas médicas Actualizado en diciembre de 2014
}

\section{Recommendations for the conduct, reporting, editing, and publication of scholarly work in medical journals Updated december 2014}

Comité Internacional de Editores de Revistas Médicas (ICMJE)

I. Sobre las Recomendaciones
A. Propósito de las Recomendaciones
B. ¿Quién debe utilizar las Recomendaciones?
C. Historia de las Recomendaciones

II. Funciones y responsabilidades de los autores, colaboradores, pares evaluadores, editores, editoriales y propietarios

A. Definición del papel de autores y colaboradores
1. ¿Por qué importa la autoría?
2. ¿Quién es un autor?
3. Colaboradores no autores

B. Responsabilidades del Autor-Conflictos de interés
1. Participantes
a. Autores
b. Pares evaluadores
c. Editores y personal de la revista

2. Declaración de conflictos de interés

C. Responsabilidades en los procesos de presentación y revisión por pares

1. Autores

2. Revistas
a. Confidencialidad
b. Cronograma
c. Revisión por rares
d. Integridad

3. Pares evaluadores

D. Propietarios de la revista y libertad editorial

1. Propietarios de la revista

2. Libertad editorial

E. Protección de los participantes en la investigación

III. Asuntos de publicación y edición relacionados con la publicación en revistas médicas
A. Correcciones y control de versiones
B. Mala conducta científica, expresiones de preocupación y retractación
C. Derechos de autor
D. Publicaciones duplicadas
1. Presentación duplicada
2. Publicación duplicada
3. Publicación secundaria aceptable
4. Manuscritos basados en la misma base de datos
E. Correspondencia
F. Honorarios Traducido y publicado con autorización
escrita del International Committee of Medical
Journals Editors - ICMJE del documento
"Recommendations for de Conduct, Reporting,
Editing and publication of Scholarly Work in
Medical Journal - Update December 2014",
publicado en www.icmje.org 
G. Suplementos, ediciones temáticas y series especiales

H. Patrocinioso asociaciones

I. Publicación electrónica

J. Publicidad

K. Revistas y medios de comunicación

L. Registro de estudios clínicos

IV. Preparación del manuscrito y presentación

A. Preparación de un manuscrito para su presentación a una revista médica

1. Principios generales

2. Guías de presentación de informes

3. Secciones de manuscritos
a. Título de la página
b. Resumen
c. Introducción
d. Métodos
i. Selección y descripción de los participantes
ii. Información técnica
iii. Estadística
e. Resultados
f. Discusión
g. Referencias
i. Consideraciones generales
ii. Estilo y formato
h. Tablas
i. Ilustraciones (Figuras)
j. Unidades de medida
k. Abreviaturas y símbolos

B. Envío del manuscrito a la revista

\section{SOBRE LA RECOMENDACIONES}

\section{A. Propósito de las Recomendaciones}

El Comité Internacional de Editores de Revistas Médicas (ICMJE por sus siglas en inglés) desarrolló estas Recomendaciones para examinar la mejor práctica y los estándares éticos en la realización y presentación de investigaciones y de otros materiales publicados en revistas médicas, y con el fin de ayudar a los autores, a los editores y a otras personas involucradas en la revisión por pares y en las publicaciones bio-médicas a crear y distribuir artículos médicos claros, precisos, reproducibles y sin sesgos. Las recomendaciones también pueden proporcionar información útil sobre el proceso de edición y publicación médica para los medios de comunicación, para los pacientes y sus familias y para los lectores en general.

\section{B. Quién debe utilizar las Recomendaciones?}

Estas Recomendaciones están destinadas principalmente para el uso por parte de autores que deseen presentar sus trabajos para ser publicados en revistas pertenecientes al ICMJE. Muchas revistas que no pertenecen al ICMJE utilizan de manera voluntaria estas recomendaciones (véase www.icmje.org/journals.html). El ICMJE fomenta su empleo pero no tiene autoridad para controlarlo o hacerlo cumplir. En todos los casos, los autores deben utilizar estas recomendaciones junto con las instrucciones a los autores de cada revista individual. Los autores también deben consultar las guías para el informe de estudios de carácter más específico (por ejemplo, las guías CONSORT para el informe de estudios aleatorizados); ver http://equatornetwork.org.

A las revistas que siguen estas Recomendaciones se les recomienda que las integren a sus instrucciones a los autores y que hagan explícito en las mismas que éstas se ciñen a las recomendaciones del ICMJE.Las revistas que desean ser reseñadas en la página web del ICMJE como seguidoras de estas Recomendaciones deben notificarlo a la secretaría del ICMJE por correo electrónico a icmje@ acponline.org. Las revistas que en el pasado han solicitado dicha reseña pero que ya no siguen las recomendaciones del ICMJE deben utilizar el mismo medio para solicitar su eliminación de esta lista.

El ICMJE promueve la difusión amplia de estas Recomendaciones al igual que la reproducción de la totalidad de este documento con fines educativos, sin ánimo de lucro, sin tener en cuenta los derechos de autor, pero todos los usos de las Recomendaciones y del documento deben dirigir a los lectores a www.icmje.org para la versión oficial más reciente, ya que el ICMJE actualiza periódicamente las recomendaciones cuando surgen asuntos nuevos. 


\section{Historia de las Recomendaciones}

El ICMJE ha publicado varias ediciones de este documento, anteriormente conocido como Requisitos Uniformes para Manuscritos Enviados a Revistas Biomédicas (URMs por sus siglas en inglés). El URM fue publicado por primera vez en 1978 como una manera de estandarizar el formato del manuscrito y su preparación para todas las revistas. Con los años surgieron asuntos en las publicaciones que iban mucho más allá de la preparación de los manuscritos, dando lugar al desarrollo de una serie de Declaraciones Separadas sobre políticas editoriales. En 1997 se revisó el documento completo de Requisitos Uniformes; en mayo de 1999 y en mayo de 2000 se actualizaron algunas secciones. En mayo de 2001 el ICMJE revisó las secciones relacionadas con posibles conflictos de interés. En 2003 el comité revisó y reorganizó todo el documento y se incorporaron al texto las Declaraciones Separadas. En el 2010 nuevamente se revisó todo el documento. Las mencionadas versiones anteriores de este documento se pueden encontrar en la sección "Archivos" de www.icmje.org. La versión con el nuevo nombre de "Recomendaciones para la realización, presentación, edición y publicación de trabajos académicos en revistas médicas" (Recomendaciones ICMJE), fue lanzada en 2013.

\section{FUNCIONES Y RESPONSABILIDADES DE AUTORES, COLABORADORES, PARES EVALUADORES, EDITORES, EDITORIALES Y PROPIETARIOS}

\section{A. Definición de la función de los autores y colaboradores}

\section{Por qué es importante la autoría}

La autoría otorga crédito y tiene importantes implicaciones académicas, sociales y financieras. La autoría también implica responsabilidad y rendición de cuentas por el trabajo publicado. Las siguientes recomendaciones tienen por objeto garantizar que aquellos colaboradores que han hecho contribuciones intelectuales sustantivas a un artículo reciban el crédito como autores, y también que los colaboradores acreditados como autores entiendan su papel en la asunción de responsabilidad y rendición de cuentas de lo que se publica.

Debido a que la autoría no informa qué contribuciones le dan derecho a un individuo para considerarse autor, algunas revistas solicitan y publican información sobre la contribución individual de cada persona que se menciona como autor en un estudio enviado para publicación, al menos cuando se trata de una investigación original. A los editores se les recomienda desarrollar e implementar una política de contribución a la autoría, así como una política que identifique quién es el responsable de la integridad del trabajo como un todo. Tales políticas eliminan gran parte de la ambigüedad que rodea las contribuciones, aunque dejan sin resolver la cuestión de la cantidad y calidad de la contribución que califica a un individuo como autor. Debido a ello, el ICMJE ha desarrollado criterios de autoría que puedan ser utilizados por todas las revistas, incluidas las que distinguen a los autores de otros colaboradores.

\section{2. ¿Quién es un autor?}

El ICMJE recomienda que la autoría se base en los cuatro criterios siguientes:

1. Contribución sustancial a la concepción o diseño del trabajo; o a la adquisición, análisis o interpretación de datos para el trabajo; Y

2. Redacción del trabajo o revisión crítica de su contenido intelectual importante; $Y$

3. Aprobación final de la versión que se publicará; Y

4. Compromiso de ser responsable de todos los aspectos del trabajo asegurando que todos los interrogantes relativos a la exactitud $u$ honestidad de cualquier parte del trabajo han sido debidamente investigados y resueltos.

Un autor, además de ser responsable de las partes del trabajo que haya hecho, debe ser capaz de identificar cuáles coautores son responsables de otras partes específicas del trabajo. Además, los autores deben tener confianza en la honestidad de las contribuciones de sus coautores.

Cada uno de los designados como autores debe cumplir con todos los cuatro criterios de autoría, y todos aquellos que cumplan con los cuatro criterios de autoría deben ser mencionados como autores. Quienes no cumplan con todos los cuatro criterios, deben recibir reconocimientos -ver la sección II.A.3 abajo. Estos criterios de autoría buscan reservar la categoría de autor para aquellos que merecen el crédito y pueden asumir la responsabilidad por el trabajo. Estos criterios no están dirigidos a ser utilizados como un medio para descalificar de la autoría, negándoles la oportunidad de cumplir con los criterios 2 ó 3 , a los colegas que por lo demás cumplen con los criterios de autoría. Por tanto, todas las personas que cumplan con el primer criterio deben tener la oportunidad de participar en la revisión, redacción y aprobación final del manuscrito.

Las personas que realizan el trabajo son las responsables de identificar quién cumple con estos criterios y lo ideal sería hacerlo desde la planeación del trabajo, haciendo las modificaciones apropiadas a medida que éste avanza. Es responsabilidad colectiva de los autores, y no de la revista a la que se presenta el trabajo, establecer que todas las personas nombradas como autores reúnen los cuatro criterios; el papel de los editores de revistas no es el de determinar quién califica o no como autor ni arbitrar conflictos de autoría. Si no se puede llegar a un acuerdo sobre quién califica como autor, se le debe pedir a la institución o instituciones en donde se realizó el trabajo que investigue, no al editor de la revista.

Si los autores solicitan la eliminación o la adición de un autor después de la presentación o publicación del manuscrito, los editores de la revista deben solicitar una explicación y una declaración de conformidad con el cambio solicitado firmada por todos los autores mencionados incluido el autor que debe ser eliminado o agregado.

El autor correspondiente es la persona que asume la responsabilidad primaria de comunicación con la revista durante la presentación del manuscrito, la revisión por pares y el proceso de publicación, y quien garantiza que se hayan 
completado correctamente todos los requisitos administrativos de la revista, tales como la provisión de todos los detalles sobre autoría, la aprobación por el comité de ética, la documentación del registro de estudios clínicos y la recolección de los formularios y declaraciones de conflictos de interés, aun cuando estas funciones hayan sido delegadas a uno o más coautores. El autor correspondiente debe estar disponible durante todo el proceso de presentación y revisión por pares para responder a las preguntas del editor de una manera oportuna, y debería estar disponible después de la publicación para responder a las críticas al trabajo y cooperar con cualquier solicitud de datos o información adicional por parte de la revista, si surgen preguntas sobre el artículo después de su publicación. Aunque el autor correspondiente es el principal responsable de la correspondencia con la revista, el ICMJE recomienda que los editores envíen copias de toda la correspondencia a todos los autores mencionados.

Cuando el trabajo ha sido realizado por un grupo grande de autores, lo ideal es que el grupo decida, antes de iniciar el trabajo, quién será un autor y que, antes de enviar el manuscrito para su publicación, confirme quién es un autor. Todos los miembros del grupo denominados autores deben cumplir con todos los cuatro criterios de autoría, incluyendo la aprobación del manuscrito final, deben ser capaces de asumir la responsabilidad pública por el trabajo y deben tener plena confianza en la exactitud y honestidad del trabajo de los otros autores grupales. También se espera que cada uno de ellos complete de manera individual las declaraciones de conflictos de interés.

Algunos grupos grandes de varios autores designan la autoría con un nombre del grupo, con o sin los nombres de los individuos. Al presentar un manuscrito con autoría grupal, el autor correspondiente debe especificar el nombre del grupo si es que existe, e identificar claramente los miembros del grupo que pueden tomar el crédito y la responsabilidad del trabajo como autores. La línea de autoría en el trabajo publicado identifica quién es el responsable directo del manuscrito, y MEDLINE lista como autor es todos los nombres que aparezcan en dicho línea. Si la línea de autoría incluye el nombre de un grupo, MEDLINE listará los nombres de los miembros del grupo como autores o como colaboradores, a veces llamados contribuyentes no autores, siempre y cuando haya una nota asociada a la línea de autoría indicando claramente que los nombres individuales de los miembros del grupo se encuentran en otra parte del artículo y si ellos son autores o colaboradores.

\section{Colaboradores No autores}

Los colaboradores que cumplen menos de los cuatro criterios anteriores para la autoría no deben aparecer como autores, pero deben ser reconocidos. Ejemplos de actividades que por sí solas (sin otros aportes) no califican a un colaborador para autoría son la adquisición de fondos, la supervisión general de un grupo de investigación o el apoyo administrativo en general, y la asistencia en cuanto a la escritura, la edición técnica, corrección de estilo y la corrección de pruebas. Aquellas personas cuya participación no justifica la autoría pueden ser reconocidos de forma individual o en conjunto como un grupo bajo un solo encabezamiento (por ejemplo, "Investigadores Clínicos" o "Investigadores Participantes"), y sus contribuciones deben ser especificados (por ejemplo, "trabajaron como asesores científicos", "revisaron críticamente la propuesta del estudio ","recopilaron datos", "atendieron a los pacientes del estudio", "participaron en la escritura o edición técnica del manuscrito").

Debido a que el reconocimiento puede implicar la aprobación de los datos y de las conclusiones de un estudio por parte de personas reconocidas, se recomienda a los editores exigir que el autor correspondiente obtenga permiso por escrito de todas las personas reconocidas para figurar en los reconocimientos.

\section{B. Responsabilidades del autor - Conflicto de intereses}

La confianza del público en el proceso científico y la credibilidad de los artículos publicados dependen en parte de la forma transparente en que sean tratados los conflictos de interés durante la planificación, implementación, escritura, revisión por pares, edición y publicación de los trabajos científicos.

Existe un conflicto de intereses cuando el juicio profesional en relación con un interés primario (como el bienestar de los pacientes o a la validez de la investigación) puede ser influenciado por un interés secundario (como el beneficio económico). Las impresiones de conflicto de intereses son tan importantes como los conflictos de intereses reales.

Las relaciones financieras (tales como empleo, consultorías, propiedad de acciones u opciones de compra de acciones, honorarios, patentes y testimonio de expertos pagados) son los conflictos de intereses más fácilmente identificables y los más susceptibles de minar la credibilidad de la revista, de los autores y de la ciencia misma. Sin embargo, los conflictos pueden ocurrir por otras razones tales como las relaciones personales o rivalidades, competencia académica y creencias intelectuales. Los autores deben evitar establecer acuerdos con los patrocinadores de un estudio, ya sea éste con o sin fines de lucro, que interfieran con el acceso de los autores a todos los datos del estudio o que interfieran con su capacidad para analizar e interpretar los datos y para preparar y publicar los manuscritos de forma independiente cuándo y dónde ellos elijan.

\section{Participantes}

Todos los participantes en la revisión por pares y el proceso de publicación - no sólo autores, sino pares evaluadores, editores y miembros del consejo editorial de las revistas - deben tener en cuenta sus posibles conflictos de intereses cuando cumplan con sus funciones en el proceso de revisión y publicación del artículo y deben declarar todas las relaciones que pudieran ser vistas como potenciales conflictos de intereses. 


\section{a. Autores}

Cuando los autores envían un manuscrito de cualquier tipo o formato, son ellos los responsables de declarar todas las relaciones financieras y personales que pudieran sesgar o ser vistas como un sesgo en su trabajo. El ICMJE ha desarrollado un formulario para la declaración de conflicto de intereses con el fin de facilitar y estandarizar las declaraciones de los autores. Las revistas miembros del ICMJE exigen que los autores utilicen este formulario, y el ICMJE estimula a otras revistas para que lo adopten.

\section{b. Pares evaluadores}

En el momento de pedirle a los pares evaluadores que evalúen un manuscrito, se les debe preguntar si tienen conflictos de interés que puedan complicar su evaluación. Los pares evaluadores deben declarar a los editores cualquier conflicto de intereses que pudiera sesgar sus opiniones sobre el manuscrito, y deben abstenerse de participar en la revisión de manuscritos específicos si existe la posibilidad de tal sesgo. Los pares evaluadores no deben usar el conocimiento del trabajo que están revisando antes de su publicación para promover sus propios intereses.

\section{c. Editores y personal de la revista}

Los editores que toman las decisiones finales sobre los manuscritos deben abstenerse de participar en las decisiones editoriales si tienen conflicto de intereses o relaciones que generen potenciales conflictos con respecto a los artículos objeto del estudio. Otros miembros del personal de redacción que participen en las decisiones editoriales deben proporcionar a los editores una descripción actualizada de sus intereses financieros $\mathrm{u}$ otros conflictos (en la medida que podrían tener relación con decisiones editoriales) y abstenerse de participar en las decisiones en las que exista conflicto de intereses. El personal editorial no debe utilizar la información adquirida a través de los manuscritos para beneficio privado. Los editores deben publicar declaraciones regulares de divulgación con respecto a los posibles conflictos de intereses relacionados con los compromisos del equipo editorial. Los editores invitados deben seguir estos mismos procedimientos.

\section{Declaración de conflicto de intereses}

Los artículos deben ser publicados con las declaraciones o documentos de soporte, como el formulario de ICMJE, de conflictos de intereses, declarando:

- Los conflictos de intereses de los autores; y

- Fuentes de apoyo financiero para el trabajo, incluidos los nombres de los patrocinadores junto con las explicaciones de la función de esas fuentes en caso de participación en el diseño del estudio, recolección, análisis e interpretación de los datos, redacción del informe, la decisión de presentar el informe para su publicación, o una declaración de que la fuente de apoyo no tenía esa participación; y
- De si los autores tuvieron acceso a los datos del estudio, con una explicación de la naturaleza y el grado de acceso, incluyendo si el acceso sigue en pié.

Para apoyar las declaraciones anteriores, los editores podrán solicitar a los autores de un estudio patrocinado por un donante con interés patrimonial o financiero en sus resultados, que firmen una declaración por el estilo de"Yo tuve pleno acceso a todos los datos de este estudio y asumo la responsabilidad completa de la integridad de los datos y la exactitud de los análisis de los datos".

\section{Responsabilidades en el proceso de presentación y revisión por pares \\ 1.Autores}

Los autores deben cumplir con todos los principios de la autoría y la declaración de conflictos de intereses detallada en las secciones II A y IIB de este documento.

\section{Revistas}

\section{a. Confidencialidad}

Los manuscritos enviados a las revistas son comunicaciones privilegiadas que son propiedad privada y confidencial de los autores y éstos pueden resultar perjudicados por la divulgación prematura de cualquiera o de todos los detalles de un manuscrito.

Por este motivo, los editores no deben compartir información sobre los manuscritos con personas distintas a los autores y pares evaluadores, incluyendo si dichos manuscritos se han recibido y están en revisión, sobre su contenido y el estado en el proceso de revisión, sobre las críticas de los pares evaluadores y sobre su destino final. Las solicitudes de terceros para utilizar los manuscritos y las evaluaciones por pares para procedimientos judiciales deben ser rechazadas cortésmente, y los editores deben hacer su mejor esfuerzo para no proporcionar tal material confidencial en caso de una orden de comparecencia.

Los editores también deben dejar en claro que los pares evaluadores deben guardar de manera estrictamente confidencial los manuscritos, el material asociado y la información que éstos contienen. Los pares evaluadores y miembros del personal de redacción no deben discutir públicamente el trabajo del autor y los pares evaluadores no deben apropiarse de las ideas del autor antes de que el manuscrito sea publicado. Los pares evaluadores no deben retener el manuscrito para su uso personal y deben destruir las copias en papel de los manuscritos y eliminar las copias electrónicas después de presentar sus opiniones.

Cuando se rechaza un manuscrito, la mejor práctica de las revistas es eliminar las copias de éste de sus sistemas editoriales, a menos que su retención sea requerida por las normas locales. Las revistas que conservan copias de los manuscritos rechazados deben revelar esta práctica en su Información a los autores.

Cuando se publica un manuscrito, las revistas deben guardar copias de la presentación original, de las evaluacio- 
nes, las revisiones y la correspondencia durante al menos tres años y posiblemente a perpetuidad, dependiendo de las regulaciones locales, para ayudar a responder preguntas futuras sobre el trabajo en caso de que éstas surjan.

Los editores no deben publicar o divulgar los comentarios de los pares evaluadores sin el permiso del par evaluador y del autor. Si la política de la revista es ocultar a los autores la identidad de los pares evaluadores y sus comentarios no están firmados, esta identidad no debe ser revelada ni al autor ni a cualquier otra persona sin la expresa autorización por escrito del par evaluador.

Es posible que esta confidencialidad tenga que ser violada si se alega deshonestidad o fraude, pero en tal caso los editores deben notificar a los autores y a los pares evaluadores que tienen la intención de hacerlo; en cualquier otro caso se debe salvaguardar la confidencialidad.

\section{b. Puntualidad}

Los editores deben hacer todo lo posible para asegurar el procesamiento oportuno de los manuscritos con los recursos que tengan disponibles.

Si los editores tienen la intención de publicar un manuscrito, deben intentar hacerlo de manera oportuna y cualquier retraso planeado debe ser negociado con los autores. Si una revista no tiene la intención de proseguir con un manuscrito, los editores deben tratar de rechazarlo lo más pronto posible para permitir a los autores presentarlo a una revista diferente.

\section{c. Revisión por pares}

La revisión por pares es la evaluación crítica de los manuscritos enviados a la revista por parte de expertos que normalmente no forman parte del equipo editorial. Ya que la evaluación imparcial, independiente y crítica es una parte intrínseca de todo trabajo académico, incluyendo la investigación científica, la revisión por pares es una importante extensión del proceso científico.

Aunque el valor real de la revisión por pares ha sido ampliamente debatido, este proceso facilita el juicio justo de un manuscrito entre los miembros de la comunidad científica. En el terreno práctico, ayuda a los editores a decidir qué manuscritos son adecuados para sus revistas. La revisión por pares, además, a menudo ayuda a los autores y editores a mejorar la calidad de las publicaciones.

Es responsabilidad de la revista asegurar que existen los sistemas para la selección de los pares evaluadores adecuados. Es responsabilidad del editor garantizar que los pares evaluadores tengan acceso a todos los materiales que puedan ser relevantes para la evaluación del manuscrito, incluyendo material complementario para publicación sólo en línea y asegurar que los comentarios del par evaluador son adecuadamente valorados e interpretados en el contexto de su declaración de conflicto de intereses.

Una revista arbitrada por pares no tiene la obligación de enviar a revisión por pares los manuscritos enviados para posible publicación y tampoco tiene la obligación de seguir las recomendaciones favorables o negativas del par evaluador. Es el editor de la revista, en última instancia, el responsable de la selección del contenido de la misma, y las decisiones editoriales pueden basarse en asuntos no relacionados con la calidad del manuscrito, como, por ejemplo, la pertinencia para la revista. Un editor puede rechazar cualquier artículo en cualquier momento antes de su publicación, incluso después de su aceptación, si surgen inquietudes acerca de la honestidad del trabajo.

Las revistas pueden diferir en el número y tipo de manuscritos que envían a revisión por pares, en el número y tipo de pares evaluadores que buscan para cada manuscrito, en si el proceso de revisión por pares es abierto o ciego y en otros aspectos del proceso de revisión. Por esta razón y como un servicio para los autores, las revistas deben publicar una descripción de su proceso de revisión por pares.

Las revistas deben notificar a los pares evaluadores la decisión final de aceptar o rechazar un trabajo, y deben reconocer la contribución de los pares evaluadores a la revista. Se recomienda a los editores a compartir los comentarios de los pares evaluadores con los otros pares evaluadores del mismo artículo, para que puedan aprender unos de otros en el proceso de revisión.

Como parte de la revisión por pares, se recomienda a los editores a revisar los protocolos de investigación, los planes para el análisis estadístico si están separados del protocolo y los contratos asociados con estudios específicos del proyecto. Antes de aceptar este tipo de estudios para publicación, los editores deben recomendar a los autores a que, en el momento de la publicación o después esta, dejen a disposición del público dichos documentos. Algunas revistas pueden exigir la exhibición pública de dichos documentos como precondición de aceptación para publicación.

Los requisitos de las revistas para el análisis independiente de datos y para la disponibilidad pública de datos están en continuo cambio en el momento de esta revisión, lo cual refleja la evolución de los puntos de vista sobre la importancia de la disponibilidad de datos para la revisión por pares antes y después de la publicación. Algunos editores de revistas solicitan actualmente un análisis estadístico de los datos del estudio por parte de un bioestadígrafo independiente antes de aceptar los estudios para su publicación. Otros piden a los autores declarar si los datos del estudio están disponibles para que terceros los puedan ver o usar o reanalizar, mientras que otros recomiendan o requieren a los autores que compartan sus datos con otras personas para su revisión o re-análisis. Cada revista debe establecer y publicar sus requerimientos específicos para el análisis de datos y publicarlos en un lugar al que los autores potenciales pueden acceder fácilmente.

Algunas personas consideran que la verdadera evaluación científica por pares comienza sólo en la fecha en la que se publica un documento. De acuerdo con esto, las revistas médicas deben tener un mecanismo para que los lectores 
puedan presentar observaciones, preguntas o críticas sobre los artículos publicados, y los autores tienen la responsabilidad de responder apropiadamente y cooperar con cualquier petición de la revista con respecto a datos o información adicional si surgen preguntas sobre el artículo después de su publicación (véase la Sección III).

El ICMJE considera que los investigadores tienen el deber de conservar por lo menos durante 10 años los datos primarios y los procedimientos analíticos que sustentan los resultados publicados. El ICMJE recomienda la preservación de estos datos en un depósito de datos para asegurar su disponibilidad a largo plazo.

\section{d. Honestidad}

La decisiones editoriales deben basarse en la relevancia de un manuscrito para la revista y en la originalidad, calidad y contribución del manuscrito a la evidencia científica de cuestiones importantes. Dichas decisiones no deben estar influenciadas por intereses comerciales, relaciones o agendas personales, o hallazgos que sean negativos o que de forma creíble cuestionen las ideas aceptadas. Además, los autores deberán enviar para su publicación o poner a disposición del público, y los editores no deben excluir el considerarlos para publicación, estudios con hallazgos que no son estadísticamente significativos o que tienen resultados no concluyentes. Tales estudios pueden aportar evidencia que combinada con la de otros estudios mediante meta-análisis aún podría ayudar a responder preguntas importantes, y un registro público de tales hallazgos negativos o no concluyentes puede prevenir la replicación injustificada del esfuerzo de investigación o ser valiosa para otros investigadores que se plantean un trabajo similar.

Las revistas deben indicar claramente su proceso de apelaciones y deben tener un sistema para responder a las apelaciones y quejas.

\section{Pares evaluadores}

Los manuscritos enviados a las revistas son comunicaciones privilegiadas que son propiedad privada y confidencial de los autores y éstos pueden resultar perjudicados por la divulgación prematura de cualquiera o de todos los detalles de un manuscrito.

Los pares evaluadores, por tanto, deben mantener de manera estrictamente confidencial los manuscritos y la información que éstos contienen. Los pares evaluadores no deben discutir públicamente el trabajo de los autores y no deben apropiarse de las ideas de los autores antes de que el manuscrito sea publicado. Los pares evaluadores no deben retener el manuscrito para su uso personal y deben destruir las copias de los manuscritos después de presentar sus evaluaciones.

Se espera que los pares evaluadores respondan con prontitud las peticiones de revisión y que las presenten en el plazo acordado. Los comentarios de los pares evaluadores deben ser constructivos, honestos y respetuosos.
Los pares evaluadores deben declarar sus conflictos de intereses y abstenerse de participar en el proceso de revisión por pares si existe un conflicto de interés.

\section{Propietarios de revistas y libertad editorial 1. Propietarios de revistas}

Los propietarios y los editores de revistas médicas comparten un propósito común, pero tienen diferentes responsabilidades y a veces esas diferencias acarrean conflictos.

Es responsabilidad de los propietarios de las revistas médicas nombrar y destituir a los editores. Los propietarios deben proporcionar a los editores en el momento de su nombramiento un contrato que establezca claramente sus derechos y deberes, la autoridad, las condiciones generales de su nombramiento y los mecanismos para la resolución de conflictos. El desempeño del editor puede ser evaluado utilizando medidas acordadas mutuamente, incluyendo pero no limitándose necesariamente al número de lectores, el número de manuscritos recibidos, los tiempos de manejo antes de la publicación y otros parámetros para revistas.

Los propietarios sólo deben destituir a los editores por razones sustanciales tales como la mala conducta científica, el desacuerdo con la dirección editorial de la revista a largo plazo, el inadecuado rendimiento de acuerdo con los parámetros de desempeño acordados o conducta inapropiada, incompatible con un cargo de confianza.

Los nombramientos y destituciones se deben basar en evaluaciones por parte de un panel de expertos independiente, en lugar de un pequeño número de ejecutivos de la organización propietaria. Debido al alto valor que le da la sociedad a la libertad de expresión dentro de la ciencia, esto es especialmente necesario en el caso de despidos, sobre todo porque a menudo es responsabilidad de los editores desafiar el status quo de maneras que pueden entrar en conflicto con los intereses de los propietarios de la revista.

Una revista médica debe declarar de manera explícita su forma de gobierno y su relación con el propietario de la revista (por ejemplo, una sociedad patrocinadora).

\section{Libertad editorial}

El ICMJE adopta la definición de libertad editorial de la Asociación Mundial de Editores Médicos que sostiene que los editores en jefe tienen plena autoridad sobre todo el contenido editorial de su revista y el momento de publicación de dicho contenido. Los propietarios de la revista no deben interferir en la evaluación, selección, programación o edición de artículos individuales, ya sea directamente o mediante la creación de un entorno que influya fuertemente en dichas decisiones. Los editores deben basar las decisiones editoriales en la validez del manuscrito y en su importancia para los lectores de la revista, no en las implicaciones comerciales para la revista, y deben tener libertad para expresar puntos de vista críticos pero responsables sobre cualquier aspecto de la medicina sin temor a represalias, incluso aunque dichos puntos de vista entren en conflicto con los objetivos comerciales de la editorial. 
Los editores en jefe también deben tener la última palabra en las decisiones sobre qué anuncios o contenido patrocinado debe o no portar la revista, incluyendo suplementos, y deben tener la última palabra en el uso de la marca de la revista y en la política general en relación con el uso comercial de los contenidos de la revista.

Se recomienda a las revistas establecer un consejo editorial independiente para ayudar al editor a establecer y mantener dicha política editorial. Los editores deben buscar, según se necesite, aportes de una amplia gama de asesores tales como pares evaluadores, personal de redacción, consejo editorial y lectores, para apoyar las decisiones editoriales y las expresiones de opinión potencialmente controversiales, y los propietarios deben asegurar que exista un seguro apropiado en caso de acciones legales contra los editores y deben garantizar que esté disponible asesoramiento jurídico cuando sea necesario. Si surgen problemas legales, el editor debe informar a su asesor jurídico y al propietario tan pronto como sea posible. Los editores deben defender la confidencialidad de los autores y de los pares evaluadores (nombres y comentarios de los pares evaluadores) de conformidad con la política del ICMJE (véase la Sección II C.2 .a). Los editores deben dar todos los pasos razonables para verificar los datos de los comentarios de la revista, incluidos los de las secciones de noticias y declaraciones a los medios de comunicación social, y deben garantizar que el personal que trabaja para la revista cumpla con las mejores prácticas periodísticas, incluyendo la toma de notas en directo y la búsqueda de respuestas de todas las partes involucradas, de ser posible antes de la publicación. Este tipo de prácticas en procura de la verdad y en pro del interés público puede ser particularmente relevante en la defensa contra acusaciones legales de difamación.

Para asegurar la libertad editorial en la práctica, el editor debe tener acceso directo al más alto nivel de los propietarios, no a un gerente delegado o a un funcionario administrativo.

Los editores y organizaciones de editores están obligados a apoyar el concepto de libertad editorial y a llevar ante la atención de las comunidades internacionales, médica, académica y lega, las transgresiones importantes en contra de dicha libertad.

\section{E. Protección de los participantes en la investigación}

Al informar sobre investigación es que involucren datos sobre seres humanos, los autores deben indicar si los procedimientos seguidos han sido evaluados por el comité de evaluación responsable (institucional y nacional), o si, en caso de no haber un comité de ética formal disponible, dichos procedimientos eran acordes con la Declaración de Helsinki revisada en 2013 (www.wma.net/ en/30publications/10policies/b3/index.html). Si existen dudas sobre si la investigación se llevó a cabo de conformidad con la Declaración del Helsinki, los autores deben explicar la razón de su enfoque y demostrar que el órgano de evaluación institucional aprobó explícitamente los aspectos dudosos del estudio. La aprobación por un comité de revisión responsable no descarta que los editores se formen su propio juicio sobre si la conducta a la largo de la investigación fue apropiada.

Los pacientes tienen derecho a la privacidad, y ésta no debe ser violada sin un consentimiento informado. La información que permita la identificación de los pacientes, incluyendo nombres, iniciales o números de historia clínica, no debe ser publicada en descripciones escritas, fotografías o pedigríes a menos que la información sea esencial para fines científicos y el paciente (o sus padres o tutor) den consentimiento informado por escrito para su publicación. A este propósito, el consentimiento informado requiere que a cada paciente determinado se le muestre el manuscrito que va ser publicado. Los autores deben revelar a dichos pacientes si cualquier material que potencial pueda servir para identificarlos va a estar disponible a través de Internet o en la publicación impresa, después de la publicación. El consentimiento del paciente debe ser dado por escrito y debe ser guardado por la revista, por los autores o por ambos, de acuerdo con lo dictado por las regulaciones o leyes locales. Las leyes aplicables varían de una región a otra y las revistas deben establecer sus políticas con previa orientación legal. Dado que en las revistas que guardan el consentimiento informado se podría conocer la identidad de los pacientes, algunas revistas pueden decidir que la confidencialidad del paciente está mejor salvaguardada si es el autor quien guarda el consentimiento informado y, en su lugar, dichas revistas le exigen al autor una declaración por escrito que dé fe de que han recibido y archivado por escrito los consentimiento informados de los pacientes.

Se deben omitir los datos de identificación no esenciales. Se debe obtener el consentimiento informado siempre que haya alguna duda sobre la posibilidad de que el anonimato se pueda preservar. Por ejemplo, tapar la zona de los ojos en las fotografías de los pacientes es una protección inadecuada del anonimato. Si con el fin de evitar la identificación de los pacientes se distorsionan las características que la harían posible, los autores deben aportar garantías, y los editores deben tenerlo en cuenta, de que dichos cambios no distorsionan el contenido científico.

El requisito del consentimiento informado debe ser incluido en las instrucciones a los autores de la revista. Cuando se ha obtenido consentimiento informado, esto debe quedar indicado en el artículo publicado.

Al informar sobre experimentos con animales, los autores deben indicar si se siguieron las normas institucionales y nacionales para el cuidado y uso de animales de laboratorio. En el Consenso de la Asociación Internacional de Editores de Revistas de Veterinaria (International Association of Veterinary Editors' Consensus) “Guías sobre Ética y Bienestar Animal para los Autores" (Author Guidelines on Animal Ethics and Welfare) (www.veteditors.org/consensus-authorguidelines-on-animal-ethics-and-welfare-for-editors) se 
puede encontrar orientación adicional sobre la ética de la investigación con animales.

\section{Publicación y asuntos editoriales relacionados con la publicación en revistas médicas}

\section{A. Correcciones y control de versiones}

Los errores honestos son parte de la ciencia y de la labor editorial y exigen la publicación de una corrección cuando se detectan. Dichas correcciones son necesarias para los erroresde hecho. Los asuntos de debate se manejan mejor mediante cartas al director, bien sea como correspondencia impresa o electrónica, o como mensajes en un foro en línea patrocinado por la revista. Actualizaciones de publicaciones previas (por ejemplo, una revisión sistemática actualizada o una guía clínica) se consideran más como una nueva publicación que como una versión de un artículo publicado anteriormente.

Si se requiere una corrección, las revistas deben seguir estas mínimas normas:

- La revista debe publicar un aviso de corrección lo antes posible, detallando los cambios hechos y citando la publicación original; la corrección debe ser hecha en una página electrónica o en una página impresa numerada incluida en un sistema electrónico o en una tabla de contenido impresa para asegurar una correcta indexación.

- La revista también debe publicar una nueva versión del artículo con los detalles de los cambios hechos a la versión original y la fecha o fechas en las que se hicieron los cambios.

- La revista debe archivar todas las versiones anteriores del artículo. Este archivo puede ser directamente accesible a los lectores o puede ser puesto a disposición del lector a solicitud.

- Las versiones electrónicas previas deben establecer de manera destacada que hay versiones más recientes del artículo.

- Las citaciones deben ser hechas a la versión más reciente. Los errores suficientemente graves como para invalidar los resultados y las conclusiones de un artículo pueden requerir una retractación.

\section{B. Mala conducta científica, expresiones de preocupación y retractación}

La mala conducta científica incluye pero no está necesariamente limitada a la fabricación de datos, la falsificación de datos incluyendo la manipulación engañosa de imágenes y el plagio. Algunas personas consideran la no de publicación de los resultados de estudios clínicos y de otros estudios en humanos como una forma de mala conducta científica. Aunque cada una de estas prácticas es problemática, éstas no son equivalentes. Cada situación requiere evaluación individual realizada por las partes interesadas competentes. Cuando se alega mala conducta científica o se plantean preocupaciones sobre la conducta o la honestidad de un trabajo descrito en artículos publicados o enviados para posible publicación, el editor debe iniciar los procedimientos apropiados detallados por comités tales como el Comité de Ética en la Publicación (Committee on Publication Ethics, COPE por sus siglas en inglés) (publicationethics.org/resources/flowcharts) y puede optar por publicar una expresión de preocupación en espera de los resultados de dichos procedimientos. $\mathrm{Si}$ los procedimientos implican una investigación en la institución a la que pertenecen los autores, el editor debe tratar de obtener el resultado de dicha investigación, notificar a los lectores de los resultados si es pertinente y, si la investigación demuestra mala conducta científica, publicar una retractación del artículo. Puede haber circunstancias en las que no se demuestre mala conducta, pero se puede publicar un intercambio de cartas con el editor para destacara los lectores los asuntos del debate.

Las expresiones de preocupación y las retractaciones no deben ser simplemente una carta al editor. Más bien, deben estar referenciadas de forma prominente, aparecer en una página electrónica o de impresa numeradas incluidas en un sistema electrónico o en una tabla de contenido impresa para asegurar una correcta indexación, e incluir en su encabezamiento el título del artículo original. En la red, la retractación y el artículo original deben tener vínculos en ambas direcciones y el artículo retractado debe estar claramente etiquetado como retractado en todas sus presentaciones (Abstract, fulltext, PDF). Idealmente, los autores de la retractación deben ser los mismos que los del artículo, pero si ellos no quieren o no pueden, el editor puede, en tales circunstancias, aceptar las retractaciones por parte de otras personas responsables o, incluso, el editor puede ser el único autor de la retractación o de la expresión de preocupación. El texto de la retractación debe explicar por qué el artículo ha sido retractado e incluir una completa cita de referencia a ese artículo. Los artículos retractados deben permanecer en el dominio público y estar claramente etiquetados como retractados.

La validez del trabajo previo del autor de un artículo fraudulento no se puede suponer. Los editores pueden solicitar a la institución del autor que les asegure la validez de otros trabajos publicados en sus revistas, o pueden retractarlos. Si esto no se hace, los editores pueden optar por publicar un pronunciamiento expresando la preocupación de que la validez del trabajo publicado previamente es incierta.

La honestidad de una investigación también puede verse comprometida por metodología inadecuada que podría llevar a una retractación.

Vea los diagramas de flujo COPE para una mayor orientación sobre retractaciones y expresiones de preocupación. Vea la Sección IV.g.i. para orientarse acerca de cómo evitar hacer referencia a artículos retractados.

\section{Derechos de autor}

Las revistas deben dejar claro el tipo de derecho de autor bajo el cual se publicará el trabajo y, si la revista se reserva 
el derecho de autor, debe detallar la posición de la revista en cuanto a la transferencia de derechos de autor para todos los tipos de contenido, incluyendo audio, vídeo, protocolos y conjuntos de datos. Las revistas médicas pueden pedir a los autores que transfieran los derechos de autor a la revista. Algunas revistas requieren la transferencia de una licencia de publicación. Algunas revistas no requieren la transferencia de los derechos de autor y se basan en vehículos tales como las licencias Creative Commons. El estado de los derechos de autor de los artículos en una revista dada puede variar: algunos contenidos no pueden ser protegidos por derechos de autor (por ejemplo, los artículos escritos por los empleados de algunos gobiernos en el curso de su trabajo). Los editores pueden renunciar a los derechos de autor de otros contenidos, y algunos contenidos pueden ser protegidos en virtud de otros acuerdos.

\section{Superposición de publicaciones \\ 1. Presentaciones duplicadas}

Los autores no deben presentar el mismo manuscrito en el mismo o en diferentes idiomas de forma simultánea a más de una revista. La justificación de esta norma es el potencial de una discordancia cuando dos (o más) revistas reclaman el derecho de publicar un manuscrito que ha sido presentado simultáneamente a más de una revista y la posibilidad de que dos o más revistas emprendan, sin saberlo e innecesariamente, el trabajo de revisión por pares, la edición del mismo manuscrito y la publicación del mismo artículo.

\section{Publicación duplicada}

La publicación duplicada es la publicación de un documento que se superpone considerablemente con uno ya publicado, sin referencia clara y visible a la publicación anterior.

Los lectores de revistas médicas merecen poder confiar en que lo que están leyendo es original, a menos que haya una declaración clara de que el autor y el editor están republicando intencionalmente un artículo (que puede ser considerado como histórico o emblemático, por ejemplo). Las bases de esta posición son las leyes internacionales de derechos de autor, la conducta ética y el uso costo-efectivo de los recursos. La publicación duplicada de una investigación original es particularmente problemática, ya que puede dar lugar a una inadvertida duplicación del conteo de datos o a una inapropiada ponderación de los resultados de un único estudio, lo que distorsiona la evidencia disponible.

Cuando los autores presentan un manuscrito informando sobre un trabajo de investigación que ya ha sido en gran parte informado en un artículo publicado o que está contenido en o muy relacionado con otro artículo que se ha presentado o ha sido aceptado para su publicación en otra parte, esto debe declararse de manera precisa en la carta de presentación y los autores deben proporcionar copias del material relacionado para ayudar al editor a decidir cómo manejar el material enviado para posible publicación. Ver también la sección IV.B.
Esta recomendación no impide que una revista considere para publicación un informe completo que sigue a la publicación de un informe preliminar, tal como una carta al editor o un resumen o póster presentado en una reunión científica. Tampoco impide a las revistas el considerar un artículo que se ha presentado en una reunión científica pero que no fue publicado en su totalidad o que está siendo considerado para su publicación en actas o en un formato similar. Los informes de prensa de reuniones científicas no suelen ser considerados como infracciones de esta regla, pero pueden serlo si tales informes están enriquecidos con tablas o figuras de datos adicionales. Los autores también deben considerar de qué manera la difusión de los resultados de su trabajo en reuniones fuera de las presentaciones científicas puede reducir la prioridad que los editores de la revista asignen a su trabajo. Puede haber una excepción a este principio, cuando se requiere difundir información que tiene implicaciones inmediatas para la salud pública, pero en lo posible la difusión temprana de resultados de una investigación antes de su publicación debe ser discutida y acordada de antemano con el editor.

Compartir con los medios de comunicación pública, con agencias del gobierno o con fabricantes, la información científica descrita en un artículo o en una carta al editor que han sido aceptados pero aún no se han publicado,viola las normas de muchas revistas. Dicha notificación puede estar justificada cuando el artículo o la carta describen avances terapéuticos importantes, enfermedades de notificación obligatoria o peligros para la salud pública, como graves efectos adversos de medicamentos, vacunas, otros productos biológicos y dispositivos médicos. un informe de esta naturaleza, ya sea en forma impresa o en línea, no debe poner en peligro la publicación, pero debe ser discutido y acordado con el editor con antelación siempre que sea posible.

El ICMJE no considerará como publicación previa la publicación de los resultados de un estudio clínico en cualquier registro de estudios clínicos que cumpla con los criterios señalados en la Sección III.L. si los resultados se limitan a un resumen estructurado breve (500 palabras) o a tablas (para incluir pacientes inscritos, principales resultados y eventos adversos). El ICMJE recomienda a los autores incluir una declaración que indique que los resultados aún no han sido publicados en una revista arbitrada por pares y actualizar el registro de resultados con la cita completa de la publicación en la revista cuando los resultados sean publicados.

Los editores de varias revistas pueden acordar entre sí publicar simultánea o conjuntamente un artículo cuando consideren que al hacerlo actúan en el mejor interés de la salud pública. Sin embargo, la Biblioteca Nacional de Medicina (NLM por sus siglas en inglés) indexa por separado todas esas publicaciones conjuntas publicadas simultáneamente, por lo que los editores deben incluir una declaración aclarando a los lectores el hecho de la publicación simultánea.

Los autores que intentan hacer publicación duplicada sin dicha notificación deben esperar al menos el pronto rechazo 
del manuscrito presentado. Si el editor no pudo darse cuenta de dicha violación y el artículo ya ha sido publicado, podría justificarse la retractación del artículo con o sin la explicación o aprobación del autor.

Ver los diagramas de flujo COPE para más instrucciones sobre el manejo de publicación duplicada.

\section{Publicación secundaria aceptable}

La publicación secundaria de material publicado en otras revistas o en la red puede ser justificable y beneficiosa, especialmente cuando su intención es difundir información importante a la mayor audiencia posible (por ejemplo, guías elaboradas por agencias gubernamentales y organizaciones profesionales en el mismo o en otro idioma). La publicación secundaria también puede ser justificable por varias otras razones si se cumplen las siguientes condiciones:

1. Los autores han recibido la aprobación de los editores de ambas revistas (el editor de la publicación secundaria debe tener acceso a la versión primaria).

2. La prioridad de la publicación primaria es respetada por un intervalo de publicación negociado tanto por los editores como por los autores.

3. El artículo para publicación secundaria está destinado a un grupo diferente de lectores; una versión abreviada podría ser suficiente.

4. La versión secundaria refleja fielmente los datos e interpretaciones de la versión primaria.

5. La versión secundaria informa a los lectores, pares evaluadores y agencias de documentación que el artículo ha sido publicado en su totalidad o en parte en otro lugar, por ejemplo con una nota que podría decir: "Este artículo se basa en un estudio publicado por primera vez en [título de la revista, con la referencia completa]" y la versión secundaria cita la referencia primaria.

6. El título de la publicación secundaria debe indicar que se trata de una publicación secundaria (reedición completa o abreviada o traducción) de una publicación primaria. Es de destacar que la NLM no considera que las traducciones sean "re-publicaciones" y no las cita o indexa cuando el artículo original ha sido publicado en una revista indexada en MEDLINE.

Cuando la misma revista publica simultáneamente un artículo en varios idiomas, la cita en MEDLINE tomará nota de los múltiples idiomas (por ejemplo, Angelo M. Journal networking in nursing: a challenge to be shared. Rev Esc Enferm USP. 2011 Dec 45[6]:1281-2,1279- 80,1283-4. Article in English, Portuguese, and Spanish. No abstract available. PMID 22241182).

\section{Manuscritos basados en la misma base de datos}

$\mathrm{Si}$ los editores reciben manuscritos de grupos de investigación independientes o del mismo grupo analizando el mismo conjunto de datos (por ejemplo, a partir de una base de datos pública, o revisiones sistemáticas o meta-análisis de la misma evidencia), los manuscritos deben ser consi- derados de manera independiente, ya que pueden diferir en sus métodos analíticos, conclusiones o en ambos. Si la interpretación de los datos y las conclusiones son similares, puede ser razonable aunque no obligatorio para los editores, dar preferencia al manuscrito presentado primero. Los editores pueden considerar la publicación de más de un manuscrito que se superponga de esta manera, porque los diferentes enfoques analíticos pueden ser complementarios e igualmente válidos, pero los manuscritos basados en el mismo conjunto de datos deben añadir datos sustanciales al otro manuscrito, suficientes para justificar que sean considerados como artículos separados, con una cita adecuada de las publicaciones previas sobre el mismo conjunto de datos, para garantizar la transparencia.

Los análisis secundarios de datos de estudios clínicos deben citar cualquier publicación primaria, estableciendo claramente que contienen análisis o resultados secundarios, y utilizar el mismo número de registro de identificación del estudio que el del estudio principal.

A veces en el desarrollo de estudios clínicos grandes se planea desde el principio producir numerosas publicaciones separadas con respecto a preguntas de investigación independientes, pero utilizando la misma muestra de pacientes original. En este caso, si todos los parámetros de resultados fueron definidos en el registro original, los autores pueden usar en todas las publicaciones separadas el número de registro único del estudio clínico original. Si los autores registraron varios sub-estudios como entradas separadas en por ejemplo, clinicaltrials.gov, entonces se debe dar al estudio en cuestión el identificador exclusivo del estudio. La cuestión principal es la transparencia, de modo que ésta debe ser obvia para el lector, sin importar el modelo que se use.

\section{E. Correspondencia}

Las revistas médicas deben ofrecer a los lectores un mecanismo para la presentación de comentarios, preguntas o críticas sobre los artículos publicados, por lo general, pero no necesariamente siempre, a través de una sección de correspondencia o de un foro en línea. Los autores de los artículos discutidos en la correspondencia o en un foro en línea tienen la responsabilidad de responder a las críticas sustanciales formuladas sobre su trabajo, utilizando esos mismos mecanismos y los editores deben pedirles que respondan. A los autores de la correspondencia se les debe pedir que declaren cualquier competencia o conflicto de intereses.

La correspondencia puede ser editada de acuerdo don la longitud, la corrección gramatical y el estilo de la revista. Alternativamente, los editores pueden optar por poner a disposición de los lectores la correspondencia sin editar, por ejemplo mediante un sistema de comentarios en línea. Tales comentarios no se indexan en Medline, a menos que sean publicados posteriormente en una página electrónica o impresa numerada. Cualquiera que sea la manera en la que la revista se encarga de la correspondencia, debe dar a 
conocer su práctica. En todos los casos, los editores deben hacer un esfuerzo para examinar los comentarios descorteses, inexactos o difamatorios.

El debate responsable, la crítica y el desacuerdo son características importantes de la ciencia, y los editores de revistas deben estimular tal discurso, idealmente dentro de su propia revista, sobre el material que han publicado. Los editores, sin embargo, tienen la prerrogativa de rechazar la correspondencia que sea irrelevante, sin interés, o que carezca de contundencia, pero también tienen la responsabilidad de permitir que se puedan expresar muy diversas opiniones y de promover el debate.

En aras de la equidad y para mantener la correspondencia dentro de proporciones manejables, las revistas pueden establecer límites de tiempo para responder sobre el material publicado y para el debate sobre un tópico determinado.

\section{F. Honorarios}

Las revistas deben tener transparencia con respecto a sus fuentes de ingresos. Cualquier cobro o cargo requerido para el procesamiento del manuscrito o la publicación del material en la revista deberán indicarse claramente en un lugar que sea fácil de encontrar por los autores potenciales antes de presentar sus manuscritos para revisión o deben ser explicados a los autores antes de que comiencen la preparación del manuscrito para su presentación (http:// publicationethics.org/files/u7140/Principles of Transparency and Best Practice in Scholarly Publishing.pdf).

\section{G. Suplementos, ediciones temáticas y series especiales}

Los suplementos son colecciones de artículos que tienen que ver con cuestiones o temas relacionados, se publican como una edición separada de la revista o como parte de una edición regular, y pueden ser financiados por fuentes distintas al propietario de la revista. Debido a que las fuentes de financiación pueden sesgar el contenido de los suplementos a través de la elección de los temas y puntos de vista, las revistas deben adoptar los siguientes principios, que también se aplican a ediciones temáticas o a series especiales que tienen financiación externa o editores invitados:

1. Al editor de la revista se le debe dar y él debe tener plena responsabilidad por las políticas, prácticas y el contenido de los suplementos, incluyendo el control completo de la decisión al seleccionar autores, pares evaluadores y el contenido de los suplementos. No debe permitirse que la edición sea hecha por el organismo que la financia.

2. El editor de la revista tiene el derecho de nombrar a uno o más editores externos para el suplemento y debe asumir la responsabilidad sobre el trabajo de dichos editores.

3. El editor de la revista debe conservar la autoridad para enviar manuscritos del suplemento a revisión por pares y para rechazar los manuscritos presentados para el suplemento con o sin revisión externa. Estas condiciones deben informarse a los autores y a cualquier editor externo del suplemento antes de comenzar el trabajo editorial sobre éste.

4. El origen de la idea para el suplemento, las fuentes de financiación para la investigación y publicación del suplemento y los productos de la fuente de financiación relacionados con el contenido planteado en el suplemento deben indicarse claramente en el material introductorio.

5. La publicidad en los suplementos debe seguir las mismas políticas que las de la revista primaria.

6. Los editores de revistas deben permitir a los lectores distinguir sin problemas entre las páginas de las ediciones ordinarias y las páginas del suplemento.

7. Los editores de revistas y suplementos no deben aceptar favores personales o remuneración directa de los patrocinadores de los suplementos.

8. La publicación secundaria en los suplementos (la republicación de trabajos publicados en otros lugares) debe ser claramente identificada mediante la cita del artículo original y mediante el título.

9. Los mismos principios de la autoría y la divulgación de los potenciales conflictos de interés discutidos en este documento deben ser aplicados a los suplementos.

\section{H. Patrocinio o asociación}

Diversas entidades pueden buscar interacciones con revistas o editores en forma de patrocinios, asociaciones, reuniones u otro tipo de actividades. Para preservar la independencia editorial, dichas interacciones deben regirse por los mismos principios descritos anteriormente para los suplementos, ediciones temáticas y series especiales (Sección III.G).

\section{Publicación electrónica}

La mayoría de las revistas médicas se publican ahora tanto en versiones electrónicas como impresas, y algunas se publican sólo en formato electrónico. Los principios de la impresión y de la publicación electrónica son idénticos y las recomendaciones de este documento se aplican a ambas por igual. Sin embargo, la publicación electrónica proporciona oportunidades para el control de versiones y plantea cuestiones acerca de la estabilidad del enlace y la preservación del contenido que son tratadas aquí.

Las recomendaciones para correcciones y control de versiones se detallan en la Sección III.A.

La publicación electrónica permite establecer vínculos con sitios y recursos por fuera de las revistas sobre los que los editores de revistas no tienen ningún control editorial. Por esta razón, y porque podrían percibirse como que los vínculos a sitios externos implican la aprobación de dichos sitios, las revistas deben ser cautelosas con los vínculos externos. Cuando una revista establece un vínculo a un sitio externo, se debe declarar que no respalda ni se responsabiliza de ningún contenido, publicidad, productos $u$ otros materiales de los sitios vinculados y tampoco se responsabiliza por la disponibilidad de los sitios. 
La preservación permanente de los artículos de las revistas en la web de la revista o en un archivo independiente o en un depósito creíble es esencial para el registro histórico. La remoción total de un artículo del sitio web de una revista casi nunca se justifica, ya que se pueden haber descargado copias del artículo, aún cuando su publicación en línea haya sido breve. Estos archivos deben ser de libre acceso o accesibles para los miembros del archivo. Se recomienda guardarlos en múltiples archivos. Sin embargo, si es necesario retirarlo por razones legales (por ejemplo, ante una acción por difamación), la URL del artículo retirado debe contener una razón detallada para su remoción y el artículo debe ser conservado en el archivo interno de la revista.

La preservación permanente del contenido total de una revista es responsabilidad del editor de la revista, quien en el caso de terminación de la revista debe tener la certeza de que los archivos de la revista se transfieran a un tercero responsable que pueda mantener disponible el contenido.

Los sitios web de las revistas deben publicar la fecha en que fueron actualizadas por última vez las páginas web que no son del artículo, tales como la lista del personal de la revista, los miembros del consejo de redacción, y las instrucciones para los autores.

\section{J. Publicidad}

La mayoría de las revistas médicas tienen publicidad que genera ingresos para sus propietarios, pero las revistas no deben dejarse dominar por la publicidad y la publicidad no deben influir en las decisiones editoriales.

Las revistas deben tener políticas formales, explícitas y escritas sobre la publicidad, tanto en la versión impresa como en la electrónica. La mejor práctica prohíbe la venta de anuncios destinados a ser yuxtapuestos al contenido editorial sobre el mismo producto. Los anuncios deben ser claramente identificables como anuncios. Los editores deben tener plena y total autoridad para aprobar la propaganda impresa y en línea y para hacer cumplir la política de publicidad.

Las revistas no deben llevar publicidad de productos que han demostrado ser gravemente perjudiciales para la salud. Los editores deben garantizar que las normas reguladoras o industriales existentes para anuncios específicos de su país se hagan cumplir o deben crear sus propias normas. Los intereses de las organizaciones o agencias no deben controlar la publicidad clasificada ni la puesta fuera de sitios web, excepto cuando lo requiera la ley. Los editores deben considerar todas las críticas a los anuncios antes de su publicación.

\section{K. Revistas y medios de comunicación}

Las interacciones de las revistas con los medios de comunicación deben equilibrar las prioridades en competencia. El público en general tiene un interés legítimo en todo el contenido de la revista y tiene derecho a información importante dentro de un lapso de tiempo razonable y los editores tienen la responsabilidad de facilitar esto. Sin embargo, los informes de los medios de comunicación sobre investigaciones científicas antes de que éstas hayan sido totalmente evaluadas y revisadas por pares pueden conducir a la difusión de conclusiones inexactas o prematuras y los médicos en la práctica necesitan tener a su disposición los informes detallados de la investigación antes de poder aconsejar a los pacientes acerca de las conclusiones de dichos informes.

Para ayudar a este equilibrio y para evitar la publicación de noticias en los medios de comunicación general antes de la publicación original de la investigación en la revista, algunos países y algunas revistas han creado un sistema de embargo. Para los medios de comunicación, este sistema crea unas "condiciones equitativas de competencia", que la mayoría de los periodistas y escritores aprecian, ya que minimiza la presión sobre ellos para que publiquen historias antes que sus competidores cuando no han tenido tiempo para prepararlas con cuidado. La consistencia en el momento de la publicación de la información biomédica también es importante para minimizar el caos económico, ya que algunos artículos contienen información que tiene el potencial de influir en los mercados financieros. El ICMJE acepta la crítica de que los sistemas de embargo están al autoservicio de los intereses de las revistas y son un impedimento para la rápida difusión de la información científica, pero cree que los beneficios de dicho sistema de embargo superan a sus perjuicios.

Los siguientes principios se aplican igualmente a la edición impresa y a la edición electrónica y pueden ser útiles para los editores, ya que buscan establecer políticas sobre las interacciones con los medios de comunicación:

- Los editores pueden fomentar la transmisión metódica de la información médica de los investigadores al público a través de las revistas. Esto se puede lograr mediante un acuerdo con los autores de no hacer público su trabajo mientras su manuscrito esté en estudio o en espera de publicación, y un acuerdo con los medios de comunicación de no publicar noticias antes de la publicación de la investigación original en la revista, a cambio de lo cual la revista cooperará con ellos en la elaboración de noticias precisas, emitiendo por ejemplo un comunicado de prensa.

- Los editores necesitan tener en cuenta que el sistema de embargo funciona como un sistema de honor -no existe un mecanismo de cumplimiento formal o de vigilancia. La decisión de un número importante de medios de comunicación o de revistas biomédicas de no respetar el sistema de embargo llevaría a su rápida disolución.

- A pesar de la confianza de los autores en su trabajo, muy pocas investigaciones médicas tienen claras y urgentes implicaciones clínicas importantes para la salud pública como para que la noticia deba ser dada a la luz pública antes de su publicación completa en una revista. Cuando se producen estas circunstancias excepcionales, las autoridades pertinentes responsables de la salud pública deben decidir si difunden la información a los médicos y 
a los medios con antelación y deben hacerse responsables de esta decisión. Si el autor y las autoridades competentes desean tener un manuscrito considerado para publicación por una revista en particular, el editor debe ser consultado antes de cualquier lanzamiento público. Si los editores reconocen la necesidad de publicación inmediata, deben renunciar a sus políticas que limitan la publicidad previa a la publicación.

- Las políticas diseñadas para limitar la publicidad previa a la publicación no deben aplicarse a los informes en los medios de comunicación de las presentaciones en reuniones científicas o a los resúmenes de estas reuniones (vea Publicación Duplicada). Los investigadores que presenten su trabajo en una reunión científica deben sentirse libres de discutir sus presentaciones con los periodistas, pero deben ser disuadidos de ofrecer más detalles acerca del estudio presentado en la charla o deben considerar que el dar tanto detalle podría disminuir la prioridad que los editores de la revista asignen a su trabajo (vea Publicación Duplicada).

- Cuando un artículo está a punto de ser publicado, los editores o el personal de la revista deben ayudar a los medios a preparar informes precisos proporcionando nuevas resúmenes, respondiendo preguntas, suministrando por adelantado copias del artículo o refiriendo a los reporteros a los expertos apropiados. Esta ayuda debe estar supeditada a la cooperación de los medios con el momento del lanzamiento de una historia para que coincida con la publicación del artículo.

\section{Registro del estudios clínicos}

La política de registro de estudios clínicos del ICMJE se detalla en una serie de editoriales (ver Actualizaciones y Editoriales [www.icmje.org/update.html] y Preguntas Frecuentes [www.icmje.org/faq clinical.html]).

Brevemente, el ICMJE exige, como condición para considerar un manuscrito para publicación, que, si se trata de un estudio clínico, este haya sido registrado en un registro público de estudios clínicos desde el momento, o incluso antes, del primer reclutamiento de pacientes. El ICMJE recomienda que todos los editores de revistas médicas exijan dicho registro. Los editores que soliciten la inclusión de su revista en la página web de la lista de publicaciones que siguen las guías del ICMJE [icmje.org/journals.html] deben reconocer que la inclusión en la lista implica el cumplimiento de las políticas de registro de estudios clínicos del ICMJE.

El ICMJE define un estudio clínico como cualquier proyecto de investigación que asigne de manera prospectiva personas o grupos de personas a una intervención, con o sin grupos de comparación o de control simultáneos, con el fin de estudiar la relación causa-efecto entre una intervención relacionada con la salud y un resultado en salud. Las intervenciones relacionadas con la salud son las que se usan para modificar un resultado biomédico o relacionado con la salud; sus ejemplos incluyen medicamentos, proce- dimientos quirúrgicos, dispositivos, tratamientos conductuales, programas educativos, intervenciones dietéticas, intervenciones de mejoría de la calidad y modificaciones en los proceso de atención. Los resultados de salud son las medidas biomédicas o relacionadas con la salud obtenidas en pacientes o participantes, incluyendo medidas farmacocinéticas y eventos adversos. El ICMJE no define el momento de reclutamiento del primer paciente en el estudio clínico, pero la buena práctica establece que el registro debe darse en el momento del consentimiento del primer del paciente.

El ICMJE acepta registros en cualquier registro de estudios clínicos que sea un registro principal de estudios clínicos de la Plataforma Internacional de Registro de Estudios Clínicos de la OMS (WHO International Clinical Trials Registry Platform, ICTRP por sus siglas en inglés) (www.who.int/ictrp/network/primary/en/index.html) o en ClinicalTrials.gov, que es un proveedor de datos a la ICTRP de la OMS. El ICMJE respalda estos registros, ya que cumplen con varios criterios. Son accesibles al público sin costo alguno, están abiertos a todos los potenciales solicitantes de registros de estudios clínicos, son gestionados por una organización sin ánimo de lucro, tienen un mecanismo para garantizar la validez de los datos de registro y se pueden buscar electrónicamente. Un registro de estudios clínicos aceptable debe incluir como mínimo los 20 ítems del registro de datos (http://prsinfo.clinicaltrials.gov/trainTrainer/WHOICMJE-ClinTrialsgov-Cross-Ref.pdf o www.who.int/ictrp/ network/trds/en/index.html) en el momento del registro y antes del reclutamiento del primer participante. El ICMJE considera inadecuados los registros de estudios clínicos que carezcan de cualquiera de los 20 campos de datos o aquellos con campos que contengan datos no informativos. Aunque no es un tema requerido, el ICMJE recomienda a los autores incluir una declaración que indique que los resultados aún no han sido publicados en una revista revisada por pares y actualizar el registro con la cita completa de la revista cuando sean publicados los resultados.

El propósito del registro de estudios clínicos es evitar la publicación selectiva y el informe selectivo de los resultados de investigación, prevenir la duplicación innecesaria de esfuerzo investigativo, ayudar a los pacientes y al público a saber qué estudios clínicos en los que quisieran inscribirse están planeados o están en curso y ayudar a los comités de ética de la investigación que están considerando la aprobación de nuevos estudios dándoles una visión de trabajos similares y de datos relevantes para la investigación que están considerando. El registro retrospectivo, por ejemplo en el momento de la presentación de manuscritos, no cumple ninguno de estos propósitos. Estos efectos también se aplican a las investigaciones con diseños diferentes, por ejemplo, estudios de observación. Por esa razón, el ICMJE recomienda el registro de investigaciones con diseños que no son de estudio clínico, pero por el hecho de que la exposición o la intervención en investigaciones con diseños que no son de estudio clínico no es establecida por los investigadores, el ICMJE no lo exige. 
Los análisis de datos secundarios de estudios clínicos no deben ser registrados como estudios clínicos independientes, sino que, por el contrario, deben referirse al número de registro de estudio clínico del estudio clínico inicial.

El ICMJE recomienda la publicación de los resultados de los estudios clínicos en los registros de estudios clínicos, pero no la exige. El ICMJE no considerará como publicación previa la publicación de los resultados del estudio clínico en cualquier registro que cumpla con los criterios anteriores, siempre y cuando los resultados se limiten a un resumen estructurado breve (500 palabras), o a tablas (para incluir pacientes inscritos, resultados claves y eventos adversos).

El ICMJE recomienda que las revistas publiquen al final del resumen del artículo publicado el número de registro del estudio clínico. El ICMJE también recomienda que siempre que un número de registro esté disponible, los autores escriban este número la primera vez que utilicen un acrónimo de estudio clínico para referirse ya sea al estudio clínico que están informando o a otros estudios clínicos que mencionen en el manuscrito.

Los editores pueden considerar si las circunstancias implicadas en el fracaso para registrar debidamente un estudio clínico posiblemente se debieron al intento de dar información sesgada o si dieron lugar a esta. Si se hace una excepción al registro prospectivo de estudios clínicos, el estudio clínico debe ser registrado posteriormente y los autores deben indicar en la publicación cuándo se completó el registro y por qué se había retrasado. Los editores deben publicar una declaración explicando por qué se permitió una excepción. El ICMJE hace énfasis en que tales excepciones deben ser raras, y que los autores que no registren un estudio clínico de manera prospectiva se arriesgan a no ser admitidos en nuestras revistas.

\section{PREPARACIÓN Y PRESENTACIÓN DE UN MANUSCRITO}

\section{A. Preparación de un manuscrito para su presentación a una revista médica \\ 1.Principios generales}

El texto de los artículos en los que se informan investigaciones originales generalmente se divide en las secciones: Introducción, Métodos, Resultados y Discusión. Esta estructura, llamada "IMRYD", no es un formato de publicación arbitrario, sino el reflejo del proceso de descubrimiento científico. Los artículos con frecuencia necesitan subtítulos dentro de estas secciones para organizar mejor su contenido. Otro tipo de artículos tales como meta-análisis pueden requerir diferentes formatos, mientras que los informes de casos, revisiones narrativas y editoriales pueden tener formatos menos estructurados o no estructurados.

Los formatos electrónicos han creado oportunidades para añadir detalles o secciones, información por capas, vínculos transversales o extracción de partes de artículos en la versión electrónica. El material suplementario exclusivamente electrónico que acompaña un artículo debe ser presentado y enviado para revisión por los pares evaluadores de manera simultánea con el manuscrito inicial.

\section{Guías para presentar manuscritos}

Se han desarrollado guías para presentar manuscritos de diferentes diseños de estudio; los ejemplos incluyen CONSORT (www.consort-statement.org) para estudios clínicos aleatorizados, STROBE (http://strobe-statement. org/) para estudios observacionales, PRISMA (http:// prisma-statement.org/) para revisiones sistemáticas y metaanálisis y STARD (www.stard-statement.org/) para estudios de precisión diagnóstica. Se recomienda a las revistas pedir a los autores sigan estas guías, ya que ayudan a los autores a describir el estudio con los detalles suficientes para que pueda ser evaluado por los editores, pares evaluadores, lectores y otros investigadores que evalúan la literatura médica. Se recomienda a los autores de manuscritos de revisión de la literatura describir los métodos utilizados para ubicar, seleccionar, extraer y sintetizar los datos; esto es obligatorio para las revisiones sistemáticas. Unas buenas fuentes de guías para presentar manuscritos son EQUATOR Network (www.equator-network.org/home/) y el Research Reporting Guidelines and Initiatives de la National Library of Medicine (www.nlm .nih.gov/services/ research report guide.html).

\section{Secciones de los manuscritos}

Los siguientes son requisitos generales para la presentación por secciones de manuscritos de todos los tipos de de diseño de estudios y de todos los formatos de manuscrito.

\section{a. Portada}

La información general acerca de un artículo y sus autores se presenta en una portada del manuscrito y por lo general incluye el título del artículo, información sobre el autor, cualquier descargo de responsabilidad, fuentes de apoyo, número de palabras, y a veces el número de tablas y figuras.

Título del artículo. El título ofrece una descripción concisa del artículo completo y debe incluir información que, junto con el Resumen, hará posible y específica la búsqueda electrónica del artículo. Las guías para la presentación de manuscritos recomiendan, y algunas revistas lo exigen, que la información sobre el tipo de diseño del estudio forme parte del título (particularmente importante para los estudios clínicos aleatorizados y revisiones sistemáticas de la literatura y meta-análisis). Algunas revistas exigen un título corto, por lo general de no más de 40 caracteres (incluyendo letras y espacios) en la página del título o como una entrada independiente en un sistema de presentación electrónica. Los sistemas de presentación electrónica pueden restringir el número de caracteres en el título.

Datos del autor. Se deben enumerar los grados académicos más altos de cada autor, aunque algunas revistas no 
los publican. Se deben especificar el nombre del departamento o departamentos y de la institución o instituciones u organizaciones a las cuales debe ser atribuido el trabajo. La mayoría de los sistemas de presentación electrónica requieren que los autores proporcionen información completa de contacto, incluyendo correo local y direcciones de correo electrónico, pero la página del título debe incluir número de teléfono y de fax del autor correspondiente y su dirección de correo electrónico.

Descargos de responsabilidad. Un ejemplo de un descargo de responsabilidad es la declaración de un autor que las opiniones expresadas en el artículo presentado son suyas propias y no una posición oficial de la institución o del financiador.

Fuentes de financiación. Estas incluyen becas, equipos, medicamentos u otros tipos de apoyo que hayan facilitado la realización del trabajo descrito en el artículo o la redacción del artículo en sí.

Recuento de palabras. El recuento de palabras del texto del artículo, excluyendo el resumen, reconocimientos, tablas, leyendas de las figuras y referencias, permite a los editores y pares evaluadores establecer si la información contenida en el artículo justifica su longitud y si el manuscrito presentado se ajusta a los formatos de la revista y a sus límites de palabras. Un recuento de palabras del resumen, por separado, es útil por la misma razón.

Número de figuras y tablas. Algunos sistemas de presentación requieren la especificación del número de figuras y tablas antes de cargar los archivos pertinentes. Estos números permiten al personal editorial y a los pares evaluadores confirmar que todas las figuras y tablas estaban realmente incluidas en el manuscrito y, debido a que las tablas y figuras ocupan espacio, evaluar si la información proporcionada por las figuras y tablas garantiza la longitud del artículo y si el manuscrito se ajusta a límites de espacio de la revista.

Declaración de conflicto de intereses. La información de conflicto de intereses para cada autor tiene que hacer parte del manuscrito; cada revista debe desarrollar normas con respecto al formulario que debe contener esta información y sobre el sitio en donde ésta será publicada. El ICMJE ha desarrollado un formato de declaración de conflicto de intereses para ser usado por las revistas miembros del ICMJE (www.icmje.org/coi disclosure.pdf) y el ICMJE recomienda a otras revistas que lo adopten. A pesar de la disponibilidad del formato, los editores pueden requerir declaraciones de conflicto de intereses en la portada del manuscrito para ahorrarse el trabajo de recoger los formatos de cada autor antes de tomar una decisión editorial o para evitar a los colaboradores y lectores de la obra la lectura del formato de cada autor.

\section{b. Resumen}

Las investigaciones originales, las revisiones sistemáticas y los metanálisis requieren resúmenes estructurados. El resumen debe proporcionar el contexto o la base para el estudio y debe indicar el propósito del estudio, los procedimientos básicos (selección de los participantes del estudio, ajustes, medidas, métodos de análisis), los hallazgos principales (dando la magnitud específica del efecto y en lo posible su significación estadística y clínica) y las conclusiones principales. Este debe hacer hincapié en los aspectos novedosos e importantes del estudio o de las observaciones, mencionar las limitaciones importantes y no sobre-interpretar los hallazgos. Los resúmenes de estudios clínicos deben incluir elementos que el grupo CONSORT ha identificado como esenciales (www.consort-statement. org/resources/downloads/extensions/consort-extensionfor-abstracts-2008pdf/). Las fuentes de financiación deben enumerarse separadamente después del Resumen para facilitar la correcta visualización y la indexación de búsqueda de recuperación de MEDLINE.

Debido a que los resúmenes son la única parte sustantiva del artículo indexada en muchas bases electrónicas de datos y la única parte que muchos lectores leen, los autores deben asegurarse de que el resumen refleja con precisión el contenido del artículo. Infortunadamente, la información en los resúmenes a menudo difiere de la que está en el texto. Los autores y editores deben trabajar en el proceso de evaluación y revisión para asegurar que la información es consistente en ambos lugares. El formato requerido para los resúmenes estructurados difiere de una revista a otra, y algunas revistas utilizan más de un formato; los autores deben preparar sus resúmenes en el formato especificado por la revista que han elegido.

El ICMJE recomienda que las revistas publiquen el número de registro del estudio clínico al final del resumen. El ICMJE también recomienda que los autores escriban el número de registro clínico, si está disponible, la primera vez que utilicen un acrónimo de estudio clínico para referirse al estudio clínico que están reportando o para otros estudios clínicos que mencionen en el manuscrito. Si los datos han sido guardados en un depósito público, los autores deben declarar al final del resumen el nombre de la base de datos y el nombre y número del depósito.

\section{c. Introducción}

Dé un contexto o base para el estudio (es decir, la naturaleza del problema y su significado). Indique el propósito o el objetivo específico de la investigación, o la hipótesis puesta a prueba por el estudio u observación. Cite solamente referencias pertinentes, y no incluya datos o conclusiones del trabajo que está informando.

\section{d. Métodos}

El principio rector de la sección de Métodos debe ser la claridad acerca de cómo y por qué el estudio se hizo de una determinada manera. La sección de Métodos debe tender a ser suficientemente detallada para que otras personas con acceso a los datos sean capaces de reproducir los resultados. En general, la sección debe incluir sólo la 
información que estaba disponible en el momento en que el plan o el protocolo para el estudio se estaban escribiendo; toda la información obtenida durante el estudio pertenece a la sección de Resultados. Si se pagó a una organización o se la contrató para ayudar a realizar la investigación (los ejemplos incluyen la recopilación y gestión de datos)esto debe ser detallado en la sección de métodos.

La sección de métodos debe incluir una declaración indicando que la investigación fue aprobada por el comité de evaluación responsable (institucional o nacional)o que está exenta de la necesidad de ser evaluada por un comité de tal naturaleza. Si no hay ningún comité formal de ética disponible, debe incluirse una declaración indicando que la investigación se llevó a cabo de acuerdo con los principios de la Declaración de Helsinki.

\section{i. Selección y descripción de los participantes}

Describa claramente la selección de los participantes en estudios de observación o en estudios experimentales (individuos sanos o pacientes, incluyendo controles), incluya los criterios de elegibilidad, los criterios de exclusión y haga una descripción de la población de origen. Debido a queen el momento del diseño del estudio no siempre se conoce la relevancia de variables como la edad, el sexo o el origen étnico, los investigadores deben tener como objetivo en todos los tipos de estudio la inclusión de poblaciones representativas y, como mínimo, proporcionar datos descriptivos de estas y otras variables demográficas relevantes. Si el estudio se llevó a cabo involucrando a una población exclusiva, por ejemplo, de un solo sexo, los autores deben justificar el por qué, salvo en casos evidentes (por ejemplo, cáncer de próstata). Los autores deben definir cómo determinaron la raza o el origen étnico y justificar su relevancia.

\section{ii. Información técnica}

Especifique los objetivos principales y secundarios del estudio - generalmente identificados como resultados primarios y secundarios. Identifique con suficiente detalle los métodos, los equipos (dar entre paréntesis el nombre y la dirección del fabricante) y los procedimientos, para permitir que otros puedan reproducir los resultados. Dé referencias de los métodos establecidos, incluyendo métodos estadísticos (véase más adelante); proporcione referencias y descripciones breves de los métodos que se han publicado, pero que no son bien conocidos; describa los métodos nuevos o que han sido sustancialmente modificados, indicando los motivos de su uso, y evalúe sus limitaciones. Identifique con precisión todos los fármacos y productos químicos utilizados, incluyendo el nombre genérico, la dosis, y la vía de administración. Identifique de manera apropiada los nombres científicos y nombres de genes.

\section{iii. Estadística}

Describa los métodos estadísticos con suficiente detalle como para permitir a un lector versado con acceso a los datos originales juzgar su idoneidad para el estudio y verificar los resultados informados. En lo posible, cuantifique los resultados y preséntelos con indicadores apropiados de medición de error o de incertidumbre (como los intervalos de confianza). Evite depender exclusivamente de las pruebas de hipótesis estadísticas, como los valores $\mathrm{P}$, que no logran transmitir información importante sobre el tamaño y la precisión de las estimaciones de efecto. Las referencias sobre el diseño del estudio y los métodos estadísticos deben ser en lo posible a trabajos estándar (enunciando las páginas). Defina los términos estadísticos, abreviaturas y la mayoría de los símbolos. Especifique el paquete estadístico de software y las versiones utilizadas. Distinga los análisis pre-especificados de los análisis exploratorios, incluyendo los análisis de subgrupos.

\section{e. Resultados}

Presente sus resultados con una secuencia lógica en el texto, tablas y figuras, presentando primero los hallazgos principales o más importantes. No repita todos los datos de las tablas o figuras en el texto; enfatice o resuma solamente las observaciones más importantes. Proporcione los datos de todos los resultados primarios y secundarios identificados en la sección de Métodos. Los materiales extras o suplementarios y los detalles técnicos se pueden colocar en un apéndice donde resulten accesibles sin interrumpir el flujo del texto, o pueden ser publicados exclusivamente en la versión electrónica de la revista.

Dé los resultados numéricos no sólo como derivados (por ejemplo, porcentajes)sino también como números absolutos a partir de los cuales se calcularon los derivados, y especifique su importancia estadística, en caso de que la tengan. Restrinja tablas y figuras a las necesarias para explicar el tema central del artículo y para evaluar los datos de soporte. Use las gráficas como una alternativa a las tablas con muchas entradas; no duplique los datos en gráficas y tablas. Evite el uso no técnico de términos tales como "al azar" (que implica un método de aleatorización), "normal", "significativo", "correlaciones", y "muestra".

Informar datos por separado de acuerdo con variables demográficas tales como edad y sexo facilita la creación de fondos comunes de datos para subgrupos demográficos con base en muchos estudios y debe hacerse de rutina, a menos que existan razones imperiosas para no estratificar la presentación de los informes, las cuales deben ser explicadas.

\section{f. Discusión}

Haga hincapié en los aspectos nuevos e importantes del estudio y en las conclusiones que se derivan de ellos en el contexto de la totalidad de la mejor evidencia disponible. 
No repita en detalle los datos u otra información contenida en otras partes del manuscrito, como la dada en la sección introducción o resultados. Para los estudios experimentales, es útil comenzar la discusión resumiendo brevemente los principales hallazgos, y explorar luego posibles mecanismos o explicaciones para estos hallazgos, comparar y contrastar los resultados con otros estudios relevantes, establecer las limitaciones del estudio y explorar las implicaciones de los hallazgos para futuras investigaciones y para la práctica clínica.

Vincule las conclusiones con los objetivos del estudio pero evite hacer afirmaciones no calificadas y conclusiones que no estén adecuadamente respaldadas por los datos. En particular, distinga entre significación clínica y estadística, y evite hacer declaraciones sobre beneficios económicos y costos, a menos que el manuscrito incluya los datos económicos y el análisis apropiados. Evite declarar prioridad en la investigación o hacer alusión a trabajos que no se han completado. Enuncie nuevas hipótesis cuando se justifique, pero rotúlelas de forma clara.

\section{g. Referencias}

$i$. Consideraciones generales

Los autores deben aportar referencias directas a las fuentes originales de investigación siempre que sea posible. Las referencias no deben ser utilizadas por los autores, editores o pares evaluadores para promover intereses propios. Aunque las referencias a artículos de revisión pueden ser una forma eficaz de guiar a los lectores a un conjunto de literatura, los artículos de revisión no siempre reflejan con exactitud los trabajos originales. Por otro lado, listas extensas de referencias a trabajos originales sobre un tema pueden ocupar excesivo espacio. Un menor número de referencias a trabajos originales pero dirigidas a los trabajos clave a menudo sirven tanto como las listas más exhaustivas, sobre todo desde que las referencias se pueden agregar a la versión electrónica de los artículos publicados y desde que la búsqueda bibliográfica electrónica permite a los lectores recuperar literatura publicada de manera eficiente.

No utilice resúmenes de conferencias como referencias: éstos se pueden citar en el texto, entre paréntesis, pero no como notas al pie de página. Las referencias a artículos aceptados pero aún no publicados deben designarse como "en prensa" o "próximos". La información de los manuscritos presentados pero no aceptados debe ser citada en el texto como "observaciones no publicadas" con el permiso por escrito de la fuente.

Evite citar una "comunicación personal" a menos que ésta proporcione información esencial no disponible en un medio público, en cuyo caso el nombre de la persona y la fecha de la comunicación deben citarse en el texto entre paréntesis. Obtenga permiso por escrito y confirmación de la fidelidad de la fuente de una comunicación personal para artículos científicos. Algunas pero no todas las revistas comprueban la fidelidad de todas las citas de referencia; por lo tanto, en la versión publicada de los artículosa veces aparecenerrores de citación. Para minimizar tales errores, las referencias deben ser verificadas utilizando ya sea una fuente electrónica bibliográfica, como PubMed, o copias impresas de las fuentes originales. Los autores son responsables de comprobar que ninguna de las referencias cite artículos retractados, excepto en el contexto de referirse a la retractación. Para los artículos publicados en revistas indexadas en MEDLINE, el ICMJE considera a PubMed la fuente autorizada de información sobre las retractaciones. Los autores pueden identificar los artículos retractados en MEDLINE mediante la búsqueda en PubMed de "Retracted publication [pt]", donde el término "pt" entre corchetes identifica el tipo de publicación, o yendo directamente a la lista de publicaciones retractadas del PubMed (http://www.ncbi.nlm.nih. gov/pubmed?term=retracted+publication $+[\mathrm{pt}])$.

Las referencias deben estar numeradas consecutivamente en el orden en que se mencionan por primera vez en el texto. Identifique las referencias en el texto, en las tablas y en las leyendas mediante números arábigos entre paréntesis.

Las referencias citadas solamente en las tablas o ilustraciones deben ser numeradas de acuerdo con la secuencia establecida por la primera aparición en el texto de la tabla o de la figura. Los títulos de las revistas deben abreviarse de acuerdo con el estilo utilizado para MEDLINE (www.ncbi.nlm.nih.gov/ nlmcatalog/journals). Hay variación en las revistas con respecto a si se pide a los autores que citen las referencias electrónicas entre paréntesis en el texto o que las citen en referencias numeradas a continuación del texto. Los autores deben consultar este punto con la revista a la que planean presentar su trabajo.

\section{ii. Estilo y Formato}

Las referencias deben seguir las normas que se resumen en la página de la National Library of Medicine (NLM) enel documento "Recomendaciones para la Realización, Informe, Edición y Publicación de Trabajos Académicos en Revistas Médicas del Comité Internacional de Editores de Revistas Médicas: Muestras de Referencias" (International Committee of Medical Journal Editors (ICMJE) Recommendations for the Conduct, Reporting, Editing and Publication of Scholarly Work in Medical Journals: Sample References www.nlm.nih.gov/bsd/ uniform requirements.html), las cuales se encuentran 
de manera mucho mas detallada en la segunda edición de "Citando Medicina" de la NLM (Citing Medicine www.ncbi.nlm.nih.gov/books/NBK7256/). Estos recursos se actualizan con regularidad a medida que se desarrollan nuevos medios de comunicación y en la actualidad incluyen guías de citación para documentos impresos, material inédito, audio y medios visuales, material en CD-ROM, DVD o disco y material en Internet.

\section{h. Tablas}

Las tablas capturan información de manera concisa y la muestran de manera eficiente; también proporcionan información en cualquier nivel deseado de detalle y precisión. La inclusión de datos en tablas en lugar de incluirlos en el texto con frecuencia hace que sea posible reducir la longitud del texto.

Prepare las tablas de acuerdo con los requerimientos específicos de la revista; para evitar errores es mejor que las tablas se puedan importar directamente al software de la publicación de la revista. Numere las tablas consecutivamente en el orden de su primera citación en el texto y póngale a cada una un título. Los títulos de las tablas deben ser cortos pero auto-explicativos, conteniendo información que permita a los lectores comprender el contenido de la tabla sin tener que volver al texto. Asegúrese de que cada tabla esté citada en el texto.

Dé a cada columna un encabezamiento corto o abreviado. Los autores deben colocar las notas explicativas al pie de la tabla y no en el título. Explique todas las abreviaturas no estándar en las notas al pie de la tabla y si es necesario use símbolos para explicar la información. Los símbolos pueden variar de una revista a otra (letras del alfabeto o símbolos como $*, \dagger, \ddagger, \S)$, así que compruebe las instrucciones que cada revista da a los autores para la práctica requerida. Identifique las mediciones estadísticas de variaciones, como la desviación estándar y el error estándar de la media.

Si utiliza datos de otra fuente, publicada o no publicada, obtenga el permiso y reconozca totalmente a esa fuente.

Puede ser apropiado que tablas adicionales, demasiado extensas para ser publicados en forma impresa, pero que contengan datos de soporte importantes, se publiquen en la versión electrónica de la revista, se depositen en un servicio de archivo o se pongan a disposición de los lectores directamente por parte de los autores. En estos casos se debe añadir al texto una declaración apropiada que informe a los lectores que existe información adicional disponible y en donde se encuentra. Presente dichas tablas adicionales a consideración junto con el artículo para que puedan estar a disposición de los pares evaluadores.

\section{i. Ilustraciones (Figuras)}

Las imágenes digitales de ilustraciones para los manuscritos deben presentarse en un formato adecuado para la publicación impresa. La mayoría de los sistemas de envío de manuscritos contienen instrucciones detalladas sobre la calidad de las imágenes y las comprueban después de cargar el manuscrito. Cuando se envía un artículo a una revista impresa, las figuras deben ser dibujadas por un profesional y fotografiadas o enviadas como impresiones digitales de calidad fotográfica.

Para las radiografías, tomografías y otras imágenes diagnósticas, así como imágenes de muestras de patología o microfotografías, envíe archivos de imágenes digitales de alta resolución. Ya que en muchos artículos científicos se utilizan pruebas de electrotransferencia (western blot, por ejemplo) como evidencia primaria, los editores pueden exigir que las fotografías originales de las electrotransferencias sean depositadas en la página web de la revista.

Aunque algunas revistas vuelven a dibujar las figuras, muchas no lo hacen.

Por lo tanto, las letras, los números y los símbolos en las figuras deben ser claros y consistentes y lo suficientemente grandes para permanecer legibles cuando la figura sea reducida para su publicación. Las figuras deben ser hechas de la manera más auto-explicativa posible, ya que muchas serán usadas directamente en presentaciones de diapositivas. Los títulos y las explicaciones detalladas se incluirán en las leyendas y no en las ilustraciones.

Las microfotografías deben tener marcadores internos a escala. Los símbolos, flechas o letras usados en las microfotografías deben hacer contraste con el fondo. Explicite la escala interna y especifique el método de tinción en las microfotografías.

Las figuras deberán numerarse consecutivamente de acuerdo con el orden en que han sido citadas en el texto. $\mathrm{Si}$ una figura ha sido publicada previamente, reconozca la fuente original y presente el permiso por escrito del propietario de los derechos para reproducirla. Este permiso se exige de manera independiente de quien sea el autor o la editorial, con excepción de los documentos que sean de dominio público.

En el manuscrito las leyendas de las ilustraciones deben presentarse en una página separada, con los números arábigos correspondientes a cada una de las ilustraciones. Cuando se utilicen símbolos, flechas, números o letras para identificar partes de las ilustraciones, identifique y explique cada uno claramente en la leyenda.

\section{j. Unidades de medida}

Las medidas de longitud, altura, peso y volumen deben ser informadas en unidades métricas (metro, kilogramo, litro) o en sus múltiplos decimales.

La temperatura debe informarse en grados Celsius. La presión sanguínea en milímetros de mercurio, a menos que se requieran específicamente otras unidades por parte de la revista.

Existen variaciones entre las revistas en cuanto a las unidades que utilizan para informar las variables hematológicas, de química clínica y otras mediciones. Los autores deben consultar la Información para los Autores de la revista en 
particular y deben reportar la información de laboratorio tanto en el sistema local como en el Sistema Internacional de Unidades (SI por sus siglas en francés).

Los editores pueden solicitar que los autores añadan unidades diferentes o que no pertenezcan al SI, ya que las unidades del SI no se emplean universalmente. Las concentraciones de un medicamento pueden ser informadas en SI o en unidades de masa, pero se deberá indicar entre paréntesis el valor en unidades diferentes cuando sea apropiado.

\section{k. Abreviaturas y símbolos}

Utilice únicamente abreviaturas estándar; el uso de abreviaturas no estándar puede confundir a los lectores. Evite abreviaturas en el título del manuscrito. En la primera mención de un texto con abreviatura se debe escribir primero el texto completo y luego, entren paréntesis, la abreviatura que se continuará utilizando en el manuscrito para referirse a él, a menos que la abreviatura sea una unidad estándar de medida.

\section{B. Envío del manuscrito a la revista}

Los manuscritos deben ir acompañados de una carta de presentación o de un formulario de presentación a la revista adecuadamente diligenciado, que debe incluir la siguiente información:

Una declaración completa al editor sobre todos los envíos previos para posible publicación y sobre todos informes previos que pudieran considerarse como una publicación redundante del mismo trabajo o de uno muy similar. Cualquier trabajo de esta naturaleza debe ser mencionado específicamente en el nuevo artículo con su referencia respectiva. Se deben incluir copias de este material junto con el artículo presentado,con el fin de ayudar al editor a abordar la situación. Ver también la Sección III.D.2.

Una declaración de las relaciones financieras o de otro tipo que pudieran llevar a un conflicto de intereses, si esa información no se incluye en el propio manuscrito o en el formato para los autores. Ver la Sección II.B.

Una declaración sobre la autoría. Las revistas que no utilizan declaraciones de contribución individual para cada uno de los autores pueden exigir, si esa información no se ha proporcionado ya en otro formato, que la carta de presentación incluya una declaración de que el manuscrito ha sido leído y aprobado por todos los autores, que se han cumplido los requisitos de autoría como se enunció anteriormente en este documento y que cada autor cree que el manuscrito representa un trabajo honesto. Véase también la Sección II.A.

Información de contacto del autor correspondiente, es decir, del responsable de la comunicación con otros autores acerca de las revisiones y la aprobación final de las pruebas, si esa información no está ya incluida en el manuscrito.

La carta o el formulario debe informar a los editores si han surgido preocupaciones (por ejemplo, por parte de los órganos institucionales o reguladores) en cuanto a la realización de la investigación o si se ha recomendado una acción correctiva.

La carta o el formulario deben aportar además cualquier información adicional que pudiera ser útil para el editor, como el tipo o formato de artículo que tiene el manuscrito para la revista en particular. Si el manuscrito ha sido presentado previamente a otra revista, es útil incluir los comentarios previos del editor y de los pares evaluadores sobre el manuscrito presentado, junto con las respuestas del autor a esos comentarios. Los editores recomiendan a los autores a que presenten estas comunicaciones previas. Haciéndolo se puede acelerar el proceso de revisión y se estimula la transparencia y el intercambio de experiencias.

Muchas revistas ofrecen una lista de chequeo previa a la presentación del manuscrito con el fin de ayudar al autor a asegurar que todos los componentes de la presentación han sido incluidos. Algunas revistas también exigen que los autores completen listas de chequeo para los informes de ciertos tipos de estudio (por ejemplo, la lista de chequeo CONSORT para los informes de estudios clínicos aleatorizados controlados). Los autores deben fijarse si la revista utiliza dichas listas de chequeo y enviarlas junto con el manuscrito si les son solicitadas.

El manuscrito debe ir acompañado del permiso para reproducir material previamente publicado, el uso de ilustraciones publicadas previamente, información sobre personas identificables y reconocimientos o agradecimientos a diferentes personas por sus aportes al trabajo. 